\title{
Measuring Spatial Variability of Vapor Flux to Characterize Vadose-zone VOC Sources: Flow-cell Experiments
}

J. Mainhagu $^{1 *}$, C. Morrison ${ }^{1}$, M. Truex ${ }^{3}$, M. Oostrom ${ }^{3}$, and M.L. Brusseau ${ }^{1,2}$,

\author{
${ }^{1}$ Soil, Water and Environmental Science Department, \\ ${ }^{2}$ Hydrology and Water Resources Department, \\ School of Earth and Environmental Sciences \\ University of Arizona, Tucson, AZ 85721 \\ ${ }^{3}$ Energy and Environment Directorate, Pacific Northwest National Laboratory, \\ P.O. Box 999, Richland, WA 99354
}

Submitted to:

Journal of Contaminant Hydrology

\author{
Date: 30 August 2013 \\ Revised: April 2014 \\ Second Revision: July 2014
}

${ }^{*}$ Corresponding Author

VPT Paper with correction JM.docx 


\section{Abstract}

A method termed vapor-phase tomography has recently been proposed to characterize the distribution of volatile organic contaminant mass in vadose-zone source areas, and to measure associated three-dimensional distributions of local contaminant mass discharge. The method is based on measuring the spatial variability of vapor flux, and thus inherent to its effectiveness is the premise that the magnitudes and temporal variability of vapor concentrations measured at different monitoring points within the interrogated area will be a function of the geospatial positions of the points relative to the source location. A series of flowcell experiments was conducted to evaluate this premise. A well-defined source zone was created by injection and extraction of a non-reactive gas $\left(\mathrm{SF}_{6}\right)$. Spatial and temporal concentration distributions obtained from the tests were compared to simulations produced with a mathematical model describing advective and diffusive transport. Tests were conducted to characterize both areal and vertical components of the application. Decreases in concentration over time were observed for monitoring points located on the opposite side of the source zone from the local-extraction point, whereas increases were observed for monitoring points located between the local-extraction point and the source zone. The results illustrate that comparison of temporal concentration profiles obtained at various monitoring points gives a general indication of the source location with respect to the extraction and monitoring points. 
Keywords: Vapor phase tomography; Vadose zone; Source characterization; flow cell experiment; VOC. 


\section{Introduction}

The presence of volatile organic compound (VOC) contaminant sources in the vadose zone poses two primary human-health risks. One potential risk is discharge to groundwater, and the other is discharge to the land surface (vapor intrusion). These two issues are typically the primary risk drivers for decisions regarding remediation of vadose-zone systems. Hence, the development and assessment of cleanup objectives for vadose-zone sources is typically based on the impact of residual mass in the vadose zone on groundwater or vapor intrusion (e.g., EPA, 2001; USACE, 2002; Carroll et al., 2012; Brusseau et al., 2013).

The standard approach for characterizing vapor-phase contamination in the vadose zone is to measure static vapor and/or sediment concentrations. The advantages and disadvantages of sediment sampling are well established. Soil gas surveys have become the default method for measuring vapor concentrations in the vadose zone. However, it is recognized that the method has certain limitations, such as characterizing mass associated with poorly accessible regions (e.g., low-permeability zones) or characterizing temporal variability of concentrations (e.g., DeGroot and Lutenegger, 1998; Thomson and Flynn, 2000; McAlary et al., 2009). As a result of these and other issues, the soilgas survey method is typically influenced by a large degree of uncertainty with respect to characterizing source location and strength. 
The vapor-phase tomography (VPT) method was recently developed to provide three-dimensional, spatially resolved characterization of vapor flux in the vadose zone (Brusseau et al., 2011). This method involves collecting depthspecific concentration and flow-rate (or surrogate) data at multiple monitoring points during a short-term vapor extraction that is conducted at a selected location. This component can then be repeated for multiple extractions, each conducted at a different location. The VPT method is analogous to the hydraulic and pneumatic tomography tests that have been developed to characterize permeability distributions in the subsurface (e.g., Baehr and Hult, 1991; Vesselinov et al, 2001; McDermott et al. 2003; Brauchler et al., 2003; Illman et al., 2007; Ni and Yeh, 2008) and partitioning-tracer tomography developed to characterize DNAPL sources in groundwater (e.g., Yeh and Zhu, 2007, Illman and al. 2010). In contrast to the latter test, concentrations of resident constituents rather than injected tracers are monitored.

The VPT method is based on measuring the spatial variability of vapor flux, and thus inherent to its effectiveness is the premise that the magnitudes and temporal variability of concentrations measured at different monitoring points within the interrogated area will be a function of the geospatial positions of the points relative to the source location. Concomitantly, under this premise, monitoring concentration profiles for multiple wells during the test provides data that can be used to characterize the general location and strength of the source. This premise is the basis for the "integral pumping test" method that has been used to characterize contaminant sources in groundwater (e.g., Bockelmann et 
al. 2001, 2003; Bayer-Raich et al. 2004). The premise is also the basis for the "multilocation contaminant mass discharge test" method recently presented by Carroll et al. (2013) for characterizing VOC sources in the vadose zone.

The objective of this research is to test under controlled conditions the premise that monitoring concentration-time profiles for multiple wells during a vapor-extraction test provides data that can be used to characterize the general location of the source. A well-instrumented flow cell was used for the experiments. A well-defined source zone was created by continuous, steady injection and extraction of a non-reactive gas $\left(\mathrm{SF}_{6}\right)$. The magnitudes and temporal profiles of concentration are monitored at multiple locations during a local vapor-extraction event, and observed differences are used to characterize the general location of the source with respect to the extraction and monitoring points. It is hypothesized that mass fluxes from the source zone to the local extraction will impact the nature of the concentration-time profile of each monitoring point differently, depending on their relative position.

\section{Materials and Methods}

The flow cell measures $100 \mathrm{~cm}$ in height, $100 \mathrm{~cm}$ in length and $5 \mathrm{~cm}$ in width (Figure 1). The front panel is a 1-cm thick glass plate and the back plate is $1-\mathrm{cm}$ thick stainless steel. The front/back plates are attached to the flow-cell frame with stainless steel plates tightened to the structure with M3 screws and sealed using a Teflon tape gasket. The left and right sides of the flow cell are each equipped with 10 Swagelock valves. The flow cell was successfully leak 
tested, with all valves closed. All of the valves on both sides of the flowcell are kept open to the atmosphere during the experiments to represent open-boundary conditions. With 5 valves distributed over a height of $90 \mathrm{~cm}$ and the extant low water saturation, the entire profile is considered to be under atmospheric boundary condition. Additionally 4 strainless steel feet are attached to the structure to maintain the flowcell in a secure vertical position during experiments. The back panel has 81 ports with a diameter of $0.2 \mathrm{~cm}$. The unused ports are sealed with threaded Teflon plugs. The sampling ports consist of $5-\mathrm{cm}$ long perforated needles placed inside the flow cell connected to a mininert valve.

The flow cell was homogeneously packed using natural silica sand with a median grain diameter of $0.354 \mathrm{~mm}$, a bulk density of $1.8 \mathrm{~g} / \mathrm{cm}^{3}$, and a porosity of 0.32 . The estimated pore volume of the flow cell is 21.5 liters. The sand was mixed with water prior to packing to produce the equivalent water saturation of 0.25 .

\section{Source zone configuration}

A well-defined gas-phase source zone was created by a continuous, steady injection of $\mathrm{SF}_{6}$ into a selected sampling port, while simultaneously extracting from an adjacent port. This approach was used rather than an organicliquid source to minimize uncertainties associated with evaporative mass transfer and density-driven transients. The injection flowrate was always lower than the extraction flowrate, creating a stable dipole configuration. The shape of the source zone is defined by the positions of the injection and extraction points and 
the size is defined by the ratio between injection and extraction flow rates. Table 1 presents the different flow-rate ratios used for each experiment. Stable source zones are associated with ratios smaller than 1 . The $\mathrm{SF}_{6}$ concentration was 10.1 $\mathrm{mg} / \mathrm{L}$ in a balance of nitrogen. The high-pressure gas tank was connected to the injection port, and a diaphragm vacuum pump was connected to the extraction port.

\section{Experiment design}

An experiment starts with the development of the controlled source, which was generated as described above. After attaining stable conditions, the localextraction test is initiated by creating a local perturbation of the concentration field using a vacuum pump connected to one of the sampling ports on the back plate of the flow cell. This step will be referred to as the local extraction. This local extraction is set to a fixed flow rate, smaller than that of the source injection/extraction flow rate so that the local extraction does not disrupt the source setting. Vapor samples are then collected periodically from several ports at various distances from the local extraction. An example setup is presented in Figure $1 \mathrm{~b}$. The location of the local extraction will vary but the relative position of the monitoring points will remain similar: 3 to 4 close monitoring points surrounding the local extraction and one further away. Given the homogeneous nature of the flow-cell system (and the corresponding uniform flow), vapor concentration is used as representative of mass flux. 
The experiment design was devised to use the flowcell in two assessment modes- areal and vertical. An areal assessment setup was designed to test the method for characterizing the spatial distribution of the source in the areal plane. In this analogy, the source zone, local extraction point, and sampling points are considered to be at the same depth interval. The size and location of the source is varied. Given the low water saturation $(\sim 0.25)$, water migration is expected to be minimal during the time frame of the experiments, as illustrated in prior experiments and initial model simulations. A vertical assessment setup was conducted to investigate the impact of vertical variability in source location. The flow cell is considered in this case to represent a vertical segment of the vadose zone. Linear source zones are positioned along the bottom of the flow cell. This system may represent for example a source associated with a laterally-extensive lower-permeability zone occurring at depth in the vadose zone, or a source associated with a groundwater contaminant plume.

Once an experiment was concluded, fresh air was injected into the system through the ports located on one side of the flow cell. This was done for a minimum of 24 hours, equivalent to 14 pore volumes. After this flush, samples were collected and analyzed to confirm no remaining $\mathrm{SF}_{6}$.

Gas samples were collected using a 10-mL Hamilton gas-tight syringe, and injected into $22 \mathrm{~mL}$ sealed vials. All samples were analyzed via gas chromatography with an electron capture detector (Shimadzu GC-17A-ECD) and a headspace autosampler (Teledyne Tekmar 7000). The instrument settings and 
analysis conditions are presented Table 2 . The quantifiable detection limit is $\sim 10$ $\mu \mathrm{g} / \mathrm{L}$.

\section{Numerical modeling}

The fully implicit, integrated finite difference STOMP code (White and Oostrom, 2006) was used to simulate the experiments. Note that the model was used in independent-prediction (all variables known a priori), rather than calibration, mode, and no adjustments to parameters were necessary to allow for comparison with experimental results. The component conservation equations for water and air are solved simultaneously, followed by the solute (SF6) conservation equation. Solute transport was simulated using a Total Variation Diminishing scheme, minimizing numerical dispersion.

The $100-\mathrm{cm}$ long, $5-\mathrm{cm}$ wide, and $100-\mathrm{cm}$ tall flow cell was discretized in the $\mathrm{x}$ - and z-direction into 101 cells with a length of $0.5-\mathrm{cm}$ directly adjacent to each boundary and $1-\mathrm{cm}$ elsewhere. The cell length was $5 \mathrm{~cm}$ in the $y$-direction. This discretization ensured that each injection or extraction location was centered in one of the cells. This discretization was obtained after several grid refinement iterations were conducted for Exp. 1 (Table 1) until no further changes were observed in the $\mathrm{SF}_{6}$ gas transport.

The top and bottom of the flow cell were assumed to have zero-flux boundaries for all components. For the vertical boundaries, it was assumed that no water could move across, that the gas phase was under atmospheric 
conditions, and that solute transport in the gas phase occurred through a fluxtype boundary condition.

The permeability and retention parameters provided by Schroth et al. (1996) were used for the 40/50 Accusand packed in the flow cell. The gas diffusion coefficient of $\mathrm{SF}_{6}$ was $0.089 \mathrm{~cm}^{2} / \mathrm{s}$ (Werner and Hohener, 2003) and the Millington and Quirk (1961) equation was used to compute gas tortuosity. The initial water saturation was specified as 0.25 throughout the computational domain and the water was not allowed to redistribute by specifying the relative permeability to be zero. For the gas phase, the relative permeability was computed using the Mualem (1976) permeability model. The longitudinal and transverse dispersivity values were 1 and $0.1 \mathrm{~mm}$, respectively, based on values measured for the porous medium in prior research (Truex et al. 2009, Oostrom et al. 2010).

\section{Results and Discussion}

\section{Source Development}

The evolution of the concentration field created inside the flow cell over time to represent a constant source, prior to the start of the local-extraction test is illustrated in Figure 2a. In order to represent concentration field, we collected samples from the entire matrix available from the sampling ports in the back of the flowcell, then we used the software Tecplot to visualize the actual concentration field, using a color coding or contour lines. All concentrations 
reported for this and all following figures are relative to the injection concentration.

After the start of the continuous injection and extraction to create the source, the concentration field fluctuates less than $4 \%$ after the 24 -hour mark. This indicates that the concentration field is stable after 24 hours. Figure $2 b$ presents breakthrough curves for the experiment from the start of the injection/extraction to the development of the stable condition defined above. The concentration profiles exhibit asymptotic behavior soon after injection, with specific transition time dependent on the distance from the source zone, and eventually attain steady or quasi-steady state conditions.

As presented in Figure 2a, the 2D measured source concentration field compares well to the numerical simulation. The measured breakthrough curves are also in accordance with the simulated ones. The comparable results indicate that the approach used herein produced a stable source zone, and that the sample collection and analysis procedures were robust.

The results of the experiments are presented in two parts: areal-based assessment and vertical-based assessment. Table 1 presents the parameters for each experiment. As mentioned previously, the source flow rates, and injectionextraction positions are key to developing the source zone. In subsequent sections of the paper, the experiment numbers presented in Table 1 are used to distinguish source configurations. 


\section{Areal assessment}

The results obtained for the local-extraction tests, namely the concentration-time profiles obtained for the monitoring points, will be classified in three categories: steady, increasing, or decreasing. Experiment 1 represents a centrally located, small, source zone, as depicted in Figure 3a. The relative concentrations measured at the monitoring points over time, after the start of the local extraction, are plotted in Figure 3b. Differences in magnitudes of the steady state concentrations reflect differences in distance from the source, with higher concentrations indicating closer proximity. The concentration values are relatively low, ranging between 0.15 to 0.35 for all sampling points, indicating that the local extraction and the monitoring points are positioned comparatively far from the source. The small size of the source zone coupled with the location of the extraction test limits potential differences among the monitoring locations.

Experiment 2 was conducted with a larger source zone, presented in Figure 4a. Two local-extraction tests were performed with this configuration. For EXT-2A, the local-extraction point was located farther away from the source and thus was set in a low concentration area $(C<0.5)$. Conversely, the local-extraction point for EXT-2B was mid-range to the source and thus in a medium concentration area $(0.5<\mathrm{C}<0.8)$.

For EXT-2A, the concentrations remained stable or increased slightly for monitoring points $\mathrm{A} 1$ and $\mathrm{A} 2$ positioned between the local extraction and the source zone (Figure 4). Conversely, a decline in concentration is observed for monitoring point A3 positioned on the opposite side of the local-extraction point 
from the source. The concentration for monitoring point A4, which is away from both the source and the local-extraction point, remains stable. These combined observations indicate the general direction of the source zone: A3 to localextraction point to $\mathrm{A} 2$ to source.

For EXT-2B, high initial concentrations and small declines are observed for monitoring points B1 and B2 which are located between the source and the local-extraction point. The concentrations for monitoring points B3 and B4 decline significantly over time. This drop in concentration is consistent with a monitoring point located on the opposite side of the local-extraction point from the source. The high concentration values indicate a close proximity to the source and the difference in variation between monitoring points indicate the general direction of said source; B3/B4 to local extraction to B1/B2 to source.

To evaluate the impact of the local-extraction flow rate on the test response, experiment 3 (Figure 5) was conducted with a lower flow rate for the local extraction, as presented in Table 1, using a configuration similar to that used for experiment 2. The same two extraction locations were chosen to conduct the tests for this experiment. The results obtained for EXT-3A, the farsource extraction test, are similar to those obtained for experiment 2 but exhibit muted responses (smaller changes in concentrations). Such muted responses are also observed for EXT-3B compared to EXT-2B. Comparison of the two sets of results for experiments 2 and 3 illustrate the impact of the flow rate used for the local extraction, with a higher flow rate providing stronger responses as would be expected. 
Experiments 4 and 5 were conducted to examine the case of a source that is not centrally located (see Figure 6). Three local-extraction tests (EXT-4/5A, EXT-4/5B and EXT-4/5C) were conducted for both experiments, with the localextraction point located at similar distances from the source. The results of these experiments (included in Figure 7) match those of the previous tests. For example, concentrations are observed to increase in EXP-4A for monitoring points A4 and A5, located between the local-extraction point and the source. Similarly, in EXP-4B, concentrations for monitoring point B2 and B5 are observed to increase. Furthermore, a pattern of stable or decreasing concentrations is observed for the monitoring points located away from the source and the localextraction point in both experiments 4 and 5. EXT-A and EXT-B for experiments 4 and 5 can be considered as mirror experiments, since they were performed with similar configurations. The similarity of results indicates satisfactory replication.

The third extraction test is presented in Figure 7c, noted EXT-4/5C. The concentrations for every monitoring point are below 0.2 and stable for EXT-4C, which is consistent with the local-extraction point being located away from the source. Concentrations for monitoring point C3 and C5 of EXT-5C (located between the local-extraction point and the source) are higher than for $\mathrm{C} 1$ and $\mathrm{C} 4$ (located away from the source and the local-extraction point).

Applying the same principle as in previous experiments, we can locate the general direction of each source: For experiment 4, A1/A2/A3 to local-extraction point to A4/A5 to the source, and B3/B4 to the local-extraction point to B2/B5 to 
the source. Both directions point to source 1. For experiment 5, B3/B5 to localextraction point to B1 to the source, points to source 2. For EXT-7, it is designated from $\mathrm{C} 1 / \mathrm{C} 4$ to local extraction point to $\mathrm{C} 3 / \mathrm{C} 5$ to the source, which is consistent with previous observations from local-extraction test performed closer to the source, and consistent with the position of source 2 .

\section{Dual-source experiments}

The results above suggest that monitoring concentration-time profiles for multiple locations during an extraction test can provide indications of source location for single-source systems. This is anticipated to generally be a more complicated endeavor for systems with multiple sources. Experiment 6 was conducted to test the capacity to identify two discrete source areas. Two source zones were developed in the flow cell as presented in Figure 6. Both source 1 and 2 are active in experiment 6.

The concentrations observed for the monitoring points are higher than in experiments 4 and 5 because both sources are present in experiment 6 . However, steady concentrations are observed for almost all monitoring points of EXT-A. Higher concentrations observed for A4 and A5 suggest their proximity to the source, as opposed to A1, A2 and A3, being away from the source. The direction of the source in this test is $A 1 / A 2 / A 3$ to local-extraction point to $A 4 / A 5$, which is similar to the direction given for experiment 4 (only source 1). We can conclude that EXT-A is only marginally impacted by the closer source 2 . 
EXT-B is positioned closer to both sources for experiment 6 (with both sources present). An initial increase in concentration with time is observed for monitoring points B1, B2, and B5 closer to the sources, consistent with prior results. Concentrations remain steady for monitoring points B3 and B4, which are both located away from the source and the local-extraction point, with the concentration being lower for B3 (located farther away).

Extraction text EXT-C is positioned close to source 2, which is active during experiments 5 and 6 but not for experiment 4 . Hence, the concentration profile should be expected to be similar to experiment 5. Inspection of Figure 7c, shows that it is, indeed, the case. The magnitudes of the concentrations observed for the monitoring points from experiments 5 and 6 are very similar, and significantly higher than for experiment 4 . These results are consistent with those observed in the prior experiments. In the case of two sources present in the flowcell, it appears that extraction tests will present a response based on the closest of the two sources, the second source, being further away will not significantly impact the results from a single local-extraction test. However, multiple local-extraction tests can be conducted to better characterize the system in this case.

\section{Vertical assessment.}

Experiment 7 (Figure 8) presents a linear source zone set across the total length of the flow cell. Two local-extraction tests, EXT-7A and EXT-7B, were conducted to assess the response to local extractions located closer or farther 
away from the source. Similarly to previous results, minimal change in concentrations is observed for the monitoring points for the near-source test, EXT-7A (Figure 8b). A slight decrease in concentration is observed for monitoring point $A 1$, which is located far from the source and on the opposite side of the local-extraction point, consistent with prior results.

The extraction point for EXT-7B is located in the top third of the flow cell. The concentrations for monitoring point $\mathrm{B}_{4}$, located between the local extraction and the source, increases with time, whereas concentrations for monitoring point $\mathrm{B}_{1}$, away from the source, decline (Figure 8c). This behavior is consistent with prior results from the areal assessment.

Lastly, the source zone for experiment 8 (Figure 9) was set across half of the flow cell to represent the edge of a source. EXT-8A (Figure 9b) is set with a local extraction at a medium distance from the source and the concentration profiles for all monitoring points exhibit a steady decline, once again indicating the position of the source being away from the local-extraction point. Monitoring points A4 and A2 present the highest initial concentration, indicating that they are positioned between the source and the local-extraction point, their concentrations do not increase over time, though, which is not the behavior observed for the areal-focused experiments. For EXT-8B (Figure 9c), set further away from the source, monitoring point B2 present a higher concentration than the other three, indicating its position between the local-extraction point and the source. Slight declines in concentration are observed for all locations, including monitoring point B2, which is located somewhat between the source and the 
local-extraction point. The concentration decrease for this latter point is the opposite of that observed in prior experiments, and may reflect that the extraction test is located laterally away from the edge of the source, and thus likely experiences the attendant impact of additional dilution effects.

\section{Aggregate behavior analysis.}

To quantify the overall concentration responses observed in the experiments, the relative increase or decrease in concentration from the initial concentration measured for each monitoring point (i.e., relative variation) is plotted against the relative position of the monitoring point. Figure 10a represent the arbitrary values allocated to each monitoring point based on its position with respect to the local-extraction point:

-1: monitoring point on the opposite side of the local extraction point from the source

0 : monitoring point in the vicinity of the local extraction

1: monitoring point positioned between the source and the local extraction. Each monitoring point is paired with another one from the same local extraction test. As a consequence, each line presented in Figure $10 \mathrm{~b}$ is a comparison between monitoring points in the same test but with different relative positions.

Figure 10b compiles the results from all experiments displaying significant relative variations (i.e., monitoring points with no variation in concentrations were excluded). The experiment values vary from $-60 \%$ to $60 \%$. In all experiments, each line presents a positive slope, indicating that monitoring points located on 
the opposite side of the local-extraction point from the source experience a greater decrease in concentration. This overall observation, based on quantitative results from all experiments, is in agreement with the previous individual analysis of each local-extraction test.

\section{Conclusion}

The objective of this study was to test under controlled conditions the premise that monitoring concentration-time profiles for multiple wells during a vapor-extraction test provides data that can be used to characterize the general location of the source.. This is based on the hypothesis that the behavior observed for the concentration-time profile for each monitoring point will depend on the relative positions of the source, local-extraction, and monitoring points. In the case of a single source zone, decreases in concentration over time were observed for monitoring points located on the opposite side of the source zone from the local-extraction point, whereas increases were observed for monitoring points located between the local-extraction point and the source zone. However, no significant variation over time and a high constant value was observed for monitoring points located between the local-extraction point and the source when the local-extraction point was located in close proximity to the source. Low, steady concentrations were observed when the local extraction and monitoring points were positioned away from the source. The local extraction flow rate and the specific positioning of the monitoring points directly impact these observations. 
In the case of multiple sources, an extraction test will isolate the source closer to its local extraction point. If a single extraction test is influenced by two close sources it will not be able to distinguish them. Conducting multiple extraction tests throughout the area, as part of the protocol, will enhance the characterization of multiple sources. The results obtained from the flow-cell experiments indicate that monitoring vapor concentration-time profiles can be used as the basis for advanced evaluations employing tomographic analysis to help characterize vadose-zone sources.

\section{Acknowledgements}

This work was funded through the Department of Energy and the NIEHS Superfund Research Program grant no. P42 ESO4940. The authors would like to thank the members of the Contaminant Transport group for their help and support and Guzel Tartakovsky from PNNL for her help. The authors would also like to thank Thomas Wietsma of PNNL for his involvement in the design and assembly of the flow cell. We thank the reviewers for their constructive comments.

\section{References}

Baehr A, Hult M. 1991 Evaluation of unsaturated air permeability through pneumatic tests. Water Resource Research. Vol27(10), pp2605-17. 
Bayer-Raich, M., J. Jarsjo, R. Liedl, T. Ptak, and G. Teutsch. 2004. Average contaminant concentration and mass flow in aquifers from timedependent pumping well data: Analytical framework. Water Resour. Res. Vol 40: W08303. DOI: 10.1029/2004WR003095

Bockelmann, A., D. Zamfirescu, T. Ptak, P. Grathwohl, and G. Teutsch. 2003. Quantification of mass fluxes and natural attenuation rates at an industrial site with a limited monitoring network: A case study. Journal of Contaminant Hydrology vol60. pp97-121.

Bockelmann, A., T. Ptak, and G. Teutsch. 2001. An analytical quantification of mass fluxes and natural attenuation rate constants at a former gasworks site. Journal of Contaminant Hydrology vol 53. pp429-453.

Brauchler, R., R. Liedl, and P. Dietrich. 2003, A travel time based hydraulic tomographic approach, Water Resour. Res., vol 39(12)

Brusseau, M.L., K.C. Carroll, and M.J. Truex. 2011. Use of Mass-Flux Measurement and Vapor-Phase Tomography to Quantify Vadose-Zone Source Strength and Distribution, ER-201125. U.S. Department of Defense Environmental Security Technology Certification Program. http://www.serdp.org/Program-Areas/Environmental-Restoration/Contaminated- 
Groundwater/Emerging-Issues/ER-201125/ER-201125/\%28language\%29/engUS.

Brusseau, M.L., K.C. Carroll, M.J. Truex, and D.J. Becker. 2013. Characterization and Remediation of Chlorinated Volatile Organic Contaminants in the Vadose Zone. Vadose Zone J. vol 12(4). pp17. doi:10.2136/vzj2012.0137

Carroll, K.C., M. Oostrom, M.J. Truex, V.J. Rohay, and M.L. Brusseau. 2012. Assessing performance and closure for soil vapor extraction: integrating vapor discharge and impact to groundwater quality. Journal of Contaminant Hydrology. Vol 128. pp71-82.

Carroll, K.C., M.J. Truex, M.L. Brusseau, K.R. Parker, R.D. Mackley, and V.J. Rohay. 2013. Characterization of Persistent Volatile Contaminant Sources in the Vadose Zone. Groundwater monitor.remed.. Vol 33(2), pp 68-84.

DeGroot, D.J., and A.J. Lutenegger. 1998. Reliability of soil gas sampling and characterization techniques. In: Geotechnical site characterization: Proceedings of the First International Site Characterization Conference, Atlanta, GA. 19-22 Apr. 1998. Vol. 1. A.A. Balkema, Rotterdam, the Netherlands. p. 629634. 
Environmental Protection Agency (EPA). 2001. Development of Recommendations and Methods to Support Assessment of Soil Venting Performance and Closure. EPA/600/R-01/070.

Illman, W.A., Xiaoyi Liu, Andrew Craig. 2007. Steady-state hydraulic tomography in a laboratory aquifer with deterministic heterogeneity: Multi-method and multiscale validation of hydraulic conductivity tomograms, Journal of Hydrology, Vol 341(3-4) pp. 222-234

IIIman, W.A., S. J. Berg, X. Liu, and A. Massi. Hydraulic/Partitioning Tracer Tomography for DNAPL Source Zone Characterization: Small-Scale Sandbox Experiments. Environ. Sci. Technol., 2010, vol 44(22). pp 8609-8614

McAlary, T.A., P. Nicholson, H. Groenevelt, and D. Bertrand. 2009. A case study of soil-gas sampling in silt and clay-rich (low-permeability) soils. Groundwater monitor.remed.. Vol 29(1), pp144-152.

McDermott Cl, Sauter M, Liedl R. 2003. New experimental techniques for pneumatic tomographical determination of the flow and transport parameters of highly fractured porous rock samples. J Hydrol vol vol 278(1-4). pp51-63.

Millington, R.J. and J.P. Quirk. 1961. Permeability of porous solids. Transac. Faraday Soc. Vol 57. pp1200-1207. 
Mualem, Y. 1976. A new model for predicting the hydraulic conductivity of unsaturated porous media. Water Resour. Res. Vol 12. pp513-522.

Ni, C-F., Yeh, J., 2008, Stochastic inversion of pneumatic cross-hole tests and barometric pressure fluctuations in heterogeneous unsaturated formations, Adv. In water res., vol 31, pp1708-1718

Oostrom, M., Truex, M. J., Tartakovsky, G. D., \& Wietsma, T. W. (2010). Three-Dimensional Simulation of Volatile Organic Compound Mass Flux from the Vadose Zone to Groundwater. Groundwater monitor.remed.. Vol 30(3), pp4556.

Schroth, M.H., S.J. Ahearn, J.S. Selker, and J.D. Istok. 1996. Characterization of Miller-similar silica sands for laboratory hydrologic studies. Soil Sci. Soc. Am. J. Vol 60. pp1331-1339.

Thomson, N.R., and D.J. Flynn. 2000. Soil vapor extraction of perchloroethylene from the Borden aquifer. Ground Water Vol 38, pp673-688. 
Truex, M.J., Oostrom, M., Brusseau, M.L., 2009, Estimating Persistent Mass Flux of Volatile Contaminants from the Vadose Zone to Ground Water, Ground Water Monitor Remed, vol 29(2), pp 63-72

U.S. Army Corps of Engineers (USACE). 2002. Engineering and Design: Soil Vapor Extraction and Bioventing Manual. EM 1110-1-4001.

Vesselinov VV, Neuman SP, Illman WA. Three-dimensional numerical inversion of pneumatic cross-hole tests in unsaturated fractured tuff 1 . Methodology and borehole effects. Water Resour Res 2001. Vol 37(12):3001-17.

Werner, D., and P. Hohener. 2003. In situ method to measure effective and sorption-affected gas-phase diffusion coefficients in soils. Environ. Sci. Technol. 2502-2510.

White, M.D., and M. Oostrom. 2006. STOMP Subsurface Transport Over Multiple Phases, Version 4.0, User's Guide. PNNL-15782, Pacific Northwest National Laboratory, Richland, Washington.

Yeh, T.-C. J., and J. Zhu. 2007. Hydraulic/partitioning tracer tomography for characterization of dense nonaqueous phase liquid source zones, Water Resource Research, vol 43, W06435 
Table 1: Settings of the experimental apparatus and experimental parameters for each local-extraction test experiment

\begin{tabular}{|c|c|c|c|c|c|c|}
\hline \multirow[b]{2}{*}{ Experiment } & \multirow{2}{*}{$\begin{array}{c}\text { Experimental } \\
\text { assesment }\end{array}$} & \multirow{2}{*}{$\begin{array}{c}\text { Source } \\
\text { type }\end{array}$} & \multirow{2}{*}{$\begin{array}{l}\text { Source positions } \\
\text { (inj)/(ext) - (cm;cm) }\end{array}$} & \multirow{2}{*}{$\begin{array}{c}\text { Source } \\
\text { flowrates } \\
\text { (inj/ext) - } \\
\mathrm{ml} / \mathrm{min}\end{array}$} & $\begin{array}{l}\text { VPT local extraction } \\
\text { positions - }(\mathrm{cm} ; \mathrm{cm}) \\
\end{array}$ & \multirow{2}{*}{$\begin{array}{c}\text { VPT local } \\
\text { extraction } \\
\text { flowrate - } \\
\mathrm{ml} / \mathrm{min} \\
\end{array}$} \\
\hline & & & & & VPT-A VPT-B VPT-C & \\
\hline 1 & areal & Point & $(50 ; 50) /(50 ; 60)$ & $50 / 100$ & $(30 ; 30)$ & 57 \\
\hline 2 & areal & Point & $(50 ; 40) /(50 ; 60)$ & $75 / 100$ & $(20 ; 80)(40 ; 50)(30 ; 30)$ & 25 \\
\hline 3 & areal & Point & $(50 ; 40) /(50 ; 60)$ & $75 / 100$ & $(20 ; 80)(30 ; 30)$ & 57 \\
\hline 4 & areal & Point & $(30 ; 30) /(20 ; 30)$ & $37.5 / 50$ & $(20 ; 60)(60 ; 40)(50 ; 80)$ & 57 \\
\hline 5 & areal & Point & $(70 ; 70) /(80 ; 70)$ & $37.5 / 50$ & $(20 ; 60)(60 ; 40)(50 ; 80)$ & 57 \\
\hline 6 & areal & Point & $\mid(30 ; 30) /(20 ; 30)-(70 ; 70) /(80 ; 70)$ & $75 / 100$ & $(20 ; 60)(60 ; 40)(50 ; 80)$ & 57 \\
\hline 7 & Vertical & Linear & $(10$ to $90 ; 10)$ & $75 / 100$ & $(50 ; 30)(50 ; 70)$ & 57 \\
\hline 8 & Vertical & Linear & 10 to $40 ; 10)$ & $75 / 100$ & $(50 ; 50)(80 ; 50)$ & 57 \\
\hline
\end{tabular}


Table 2: GC parameters for gas sample analysis

\begin{tabular}{|c|c|}
\hline $\begin{array}{l}\text { TELEDYNE TEKMAR } 7000 \\
\text { Autosampler Parameters }\end{array}$ & $\begin{array}{c}\text { COLUMN Parameters } \\
\text { Supelco Q-PLOT Fused } \\
\text { Silica Capillary }(30 \mathrm{~m} \times 0.53 \mathrm{~mm})\end{array}$ \\
\hline Platen: $40^{\circ} \mathrm{C}$ & Initial column temperature: $40^{\circ} \mathrm{C}$ \\
\hline Platen Equilibrium: 10 min. & Minutes at $40^{\circ} \mathrm{C}: 1$ \\
\hline Sample Equilibrium: 30 min. & $10^{\circ} \mathrm{C} / \mathrm{min}$. ramp \\
\hline Vial size: $22 \mathrm{~mL}$ & Final ramp temperature: $100^{\circ} \mathrm{C}$ \\
\hline Mixer: OFF & Minutes held at $100^{\circ} \mathrm{C}: 10 \mathrm{~min}$. \\
\hline Pressure: 0.25 & Column Temperature: $50^{\circ} \mathrm{C}$ \\
\hline Pressure Equilibrium: 0.25 & Tnjector Temperature: $150^{\circ} \mathrm{C}$ \\
\hline Loop: 0.25 & Detector Temperature: $345^{\circ} \mathrm{C}$ \\
\hline Loop Equilibrium: 0.20 & Range: 1 \\
\hline Tnjection: 0.30 & Currant: 1 \\
\hline Sample Loop: $40^{\circ} \mathrm{C}$ & C Flow: $6 \mathrm{~mL} / \mathrm{min}$. \\
\hline Line: $40^{\circ} \mathrm{C}$ & Velocity: 40 \\
\hline Injection per vial: 1 & Split-Ratio (SPL-R): 5 \\
\hline GC Cycle time: $17 \mathrm{~min}$. & $\begin{array}{c}\text { Column Car1 ID: } 0.53 \text {; Length } \\
\text { (Len): } 25\end{array}$ \\
\hline Method Optimization: OFF & Injection volume: $1 \mathrm{uL}$ \\
\hline
\end{tabular}




\section{List of Figures}

Figure 1 - a) Schematic of the flow cell b) Photograph of the flow cell with an extraction configuration represented.

Figure 2 - a) Concentration field in the flow cell for three times. Simulation (color coding) and experiment (contour lines), b) Breakthrough curves for 3 different positions in the flow cell - $(X ; Y)$ in $\mathrm{cm}$ - Simulation (line) and experiment (diamond).

Figure 3 - Local extraction test experiment 1. a) Initial concentration field and extraction test configuration: A-local extraction A1 to A4-monitoring points, b) monitoring points concentration over time after start of the extraction.

Figure 4 - Local extraction test experiment 2. a) Initial concentration field and extraction test configurations: A and B- local extractions. A1 to A3 and B1 to B4 monitoring points, b) Monitoring points concentration over time after the start of each extraction test.

Figure 5 - Local extraction test experiment 3. a) Initial concentration field and extraction test configurations: $A$ and $B$ - local extractions. $A 1$ to $A 3$ and $B 1$ to $B 4$ monitoring points, b) Monitoring points concentration over time after the start of each extraction test. 
Figure 6 - Local extraction test configurations for experiments 4, 5, and 6. A, B, and $\mathrm{C}$ indicate the position of the local extraction for each extraction test, each circled respectively in blue, yellow and red. Black crosses indicate the respective monitoring points.

Figure 7 - Comparison of extraction test results for experiments 4, 5, and 6. Each extraction test is presented separately with results for experiment 4,5 , and 6 represented by cross, triangle, and square symbols, respectively. Monitoring points for each extraction test are identical in each experiment and numbered from 1 to 5 (see insert). The results for each monitoring point are presented separately in the five individual data figures, a) EXT-A, b) EXT-B, c) EXT-C.

Figure 8 - Local extraction test experiment 7. a) Initial concentration field and extraction test configurations. The linear source zone is set by the main injection and extraction represented by the arrows. A and B local extraction. A1 to A4 and B1 to B4 - monitoring points, b) Monitoring points concentration over time for EXT-A, c) Monitoring points concentration over time for EXT-B.

Figure 9 - Local extraction test experiment 8. a) Initial concentration field and extraction test configurations. The linear source zone is set by the main injection and extraction represented by the arrows. A and B- local extraction. A1 to A4 and B1 to B4 - monitoring points, b) Monitoring points concentration over time for EXT-A, c) Monitoring points concentration over time for EXT-B. 
Figure 10 - Relative variation of monitoring point concentrations against arbitrary position in the local extraction test. a) Schematic explaining the monitoring point position values $b$ ) results across experiments $c$ ) results across simulations. 


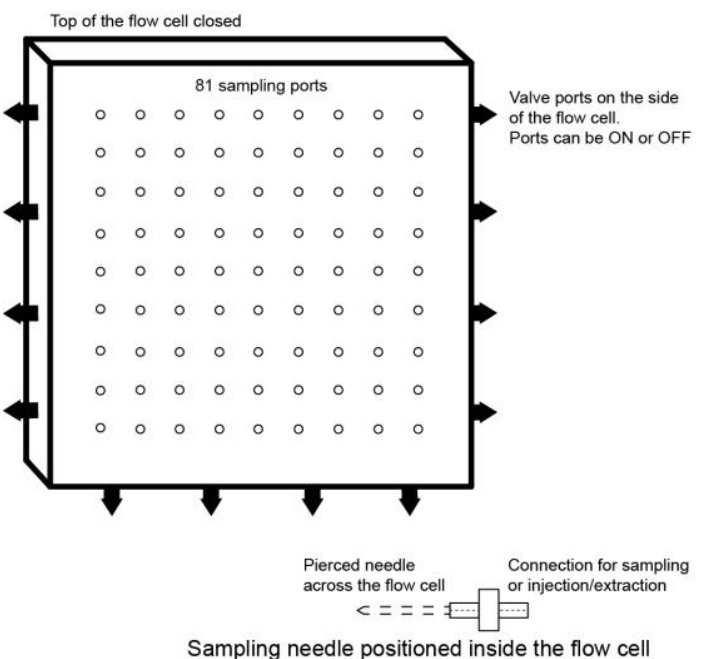

a) Schematic of the flow-cell

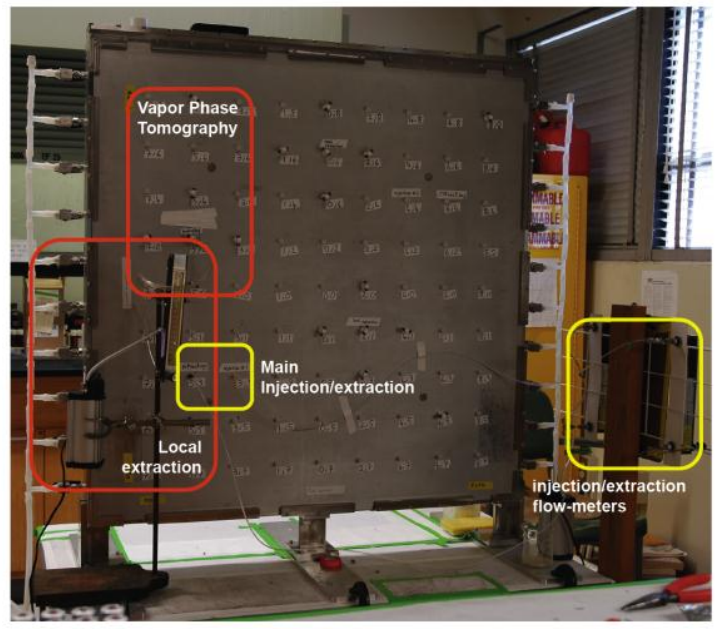

b) Picture of the back of the flow cell with a Vapor Phase Tomography local extraction installed 

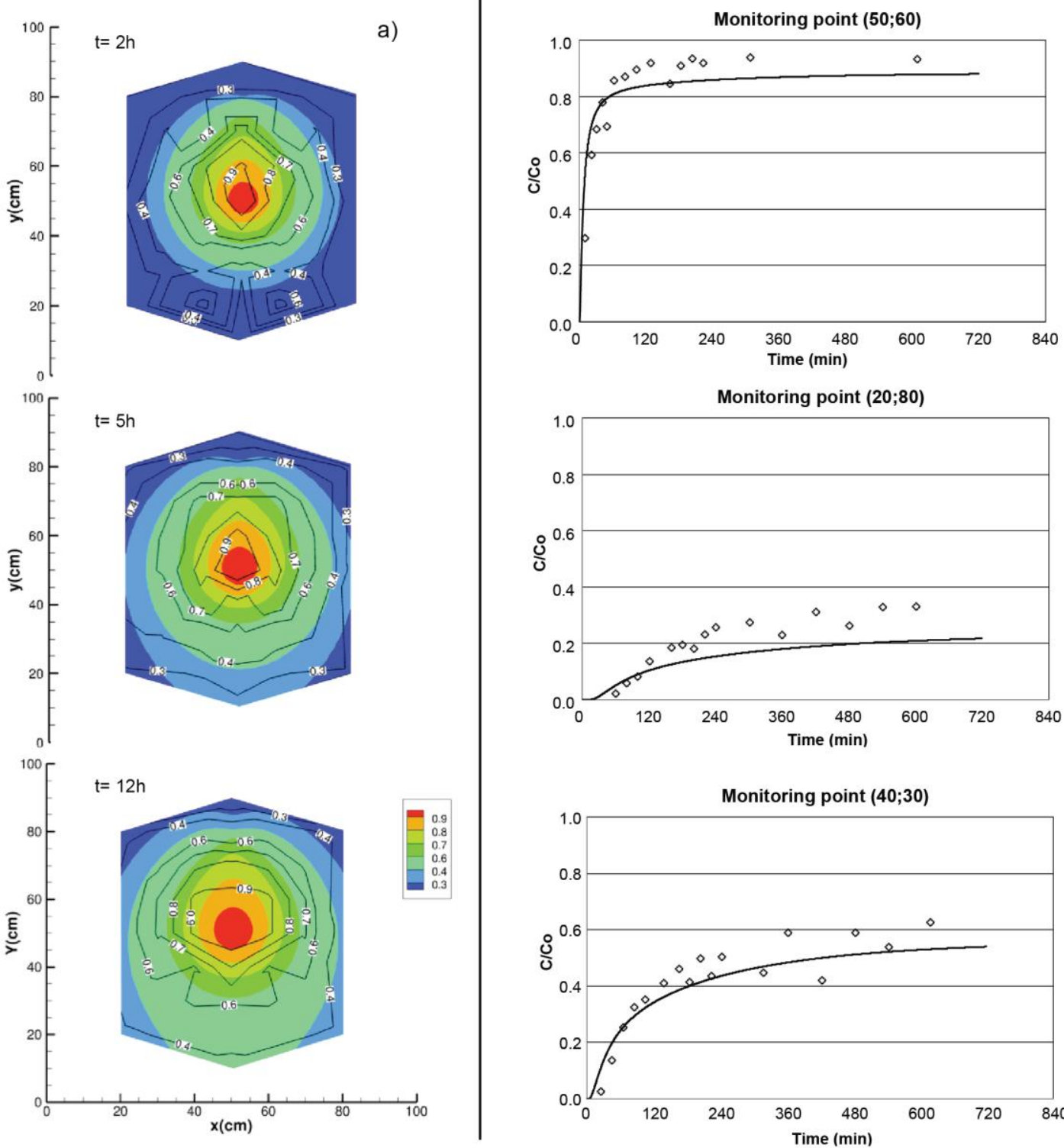

b)
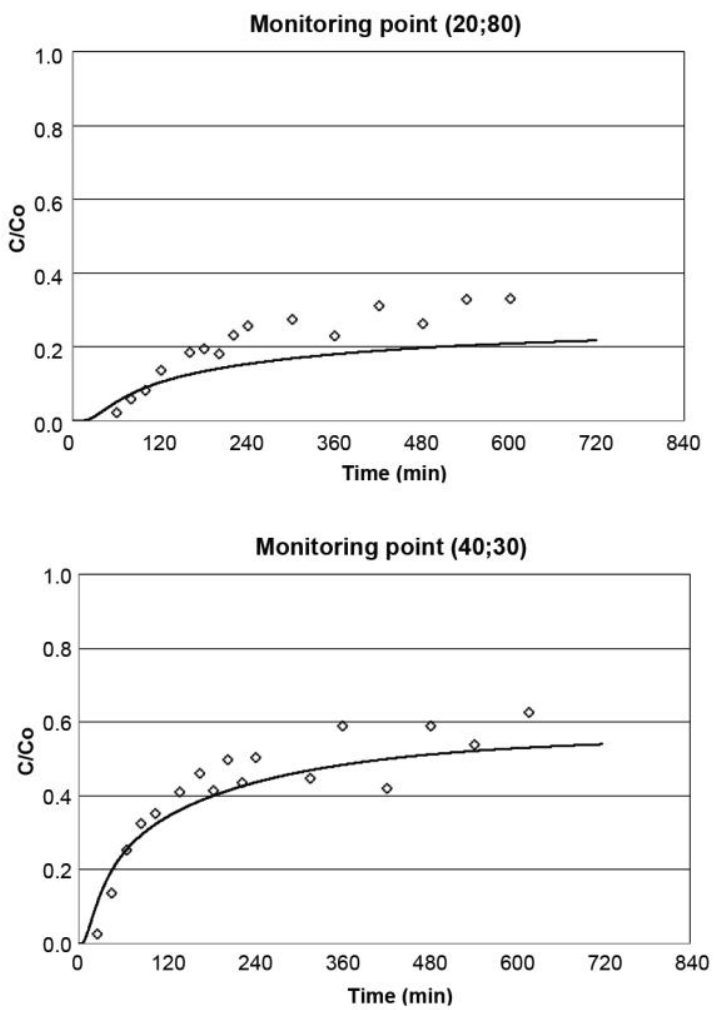
a)
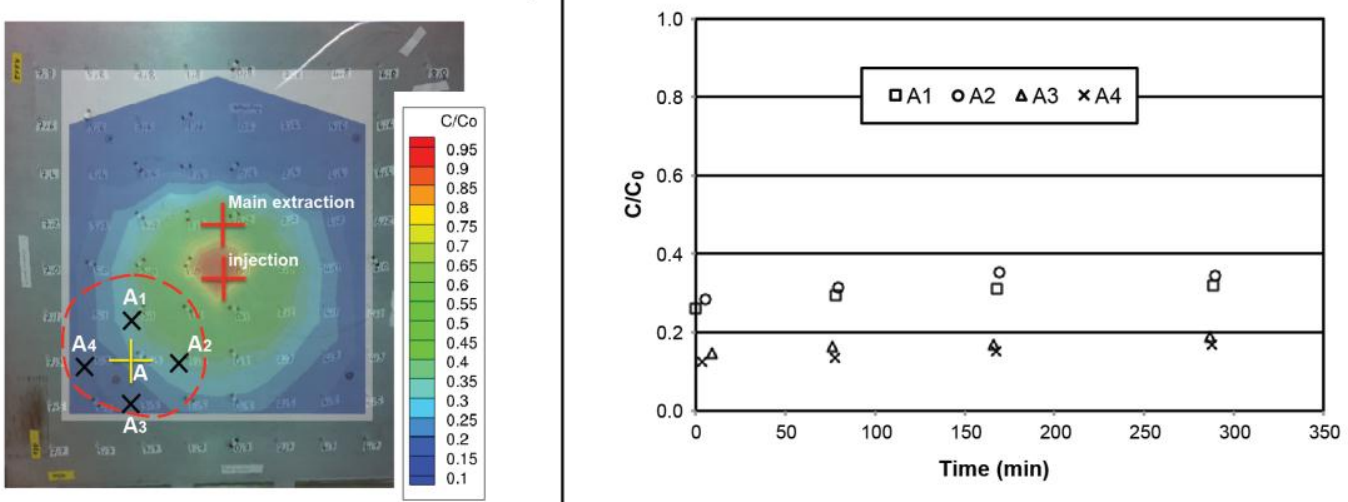

b) 
a)

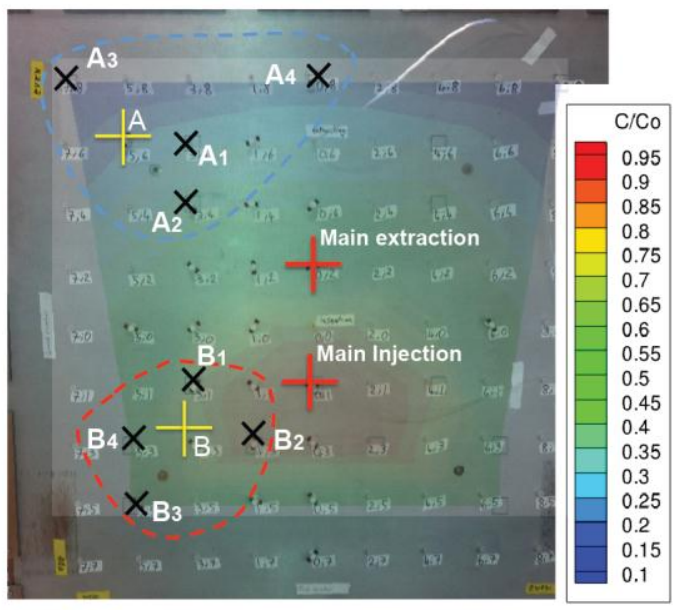

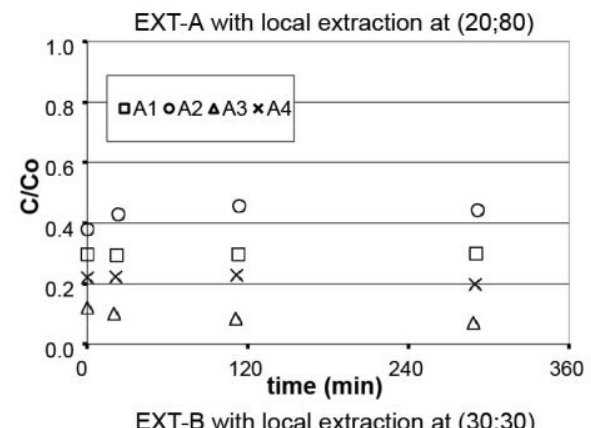

b)

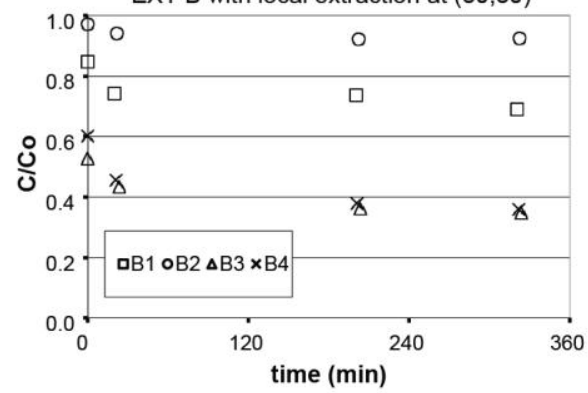



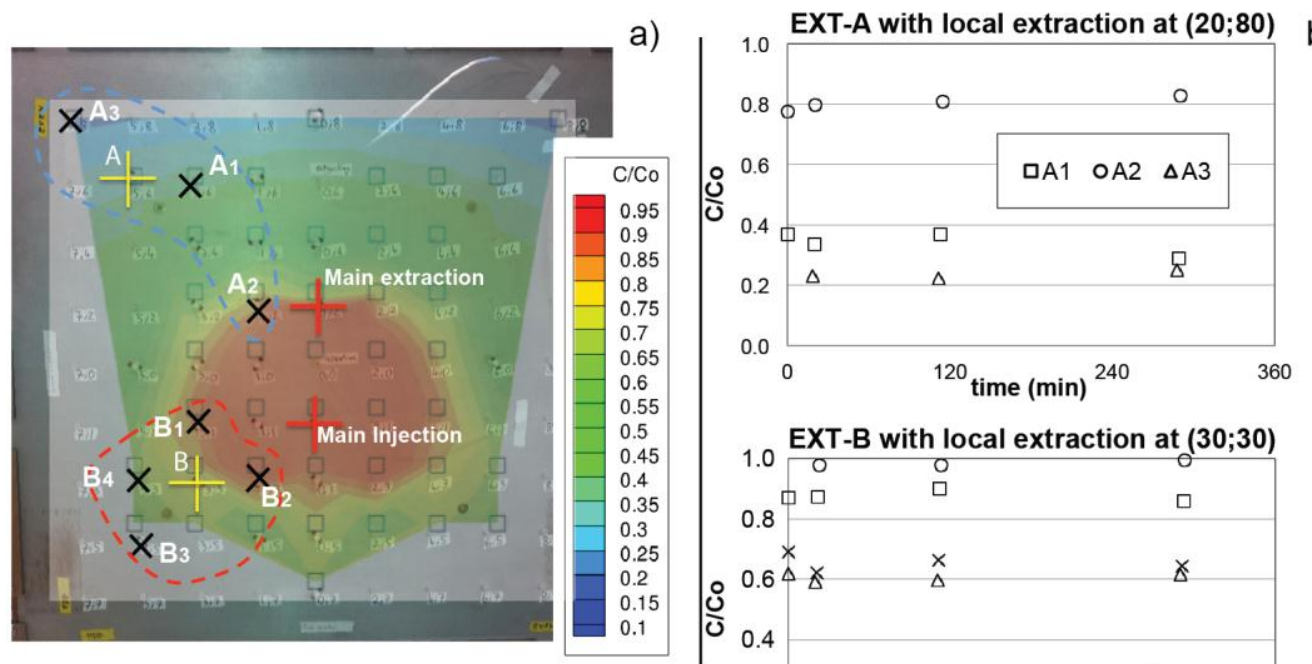

b)

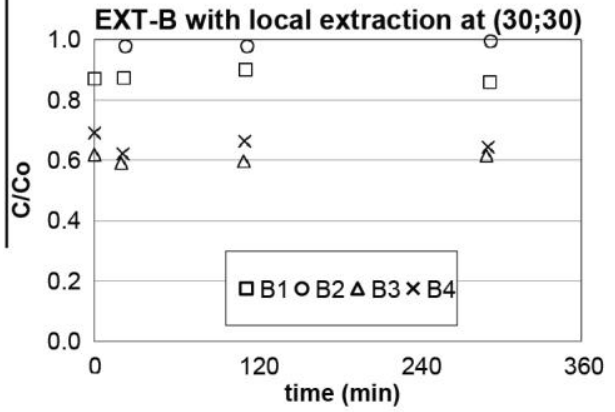



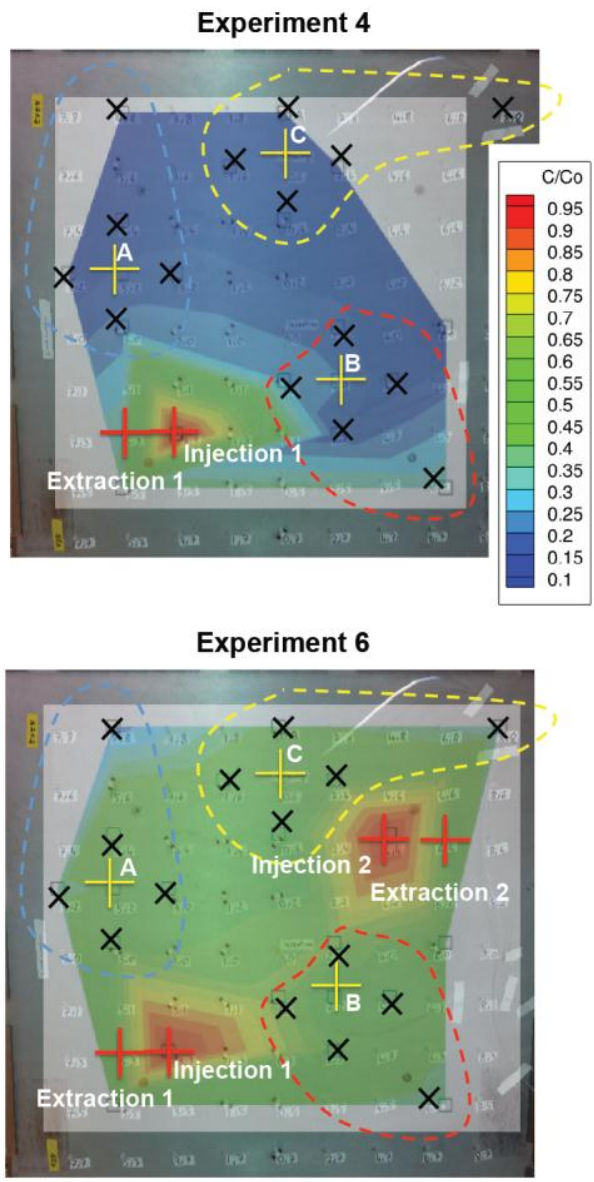

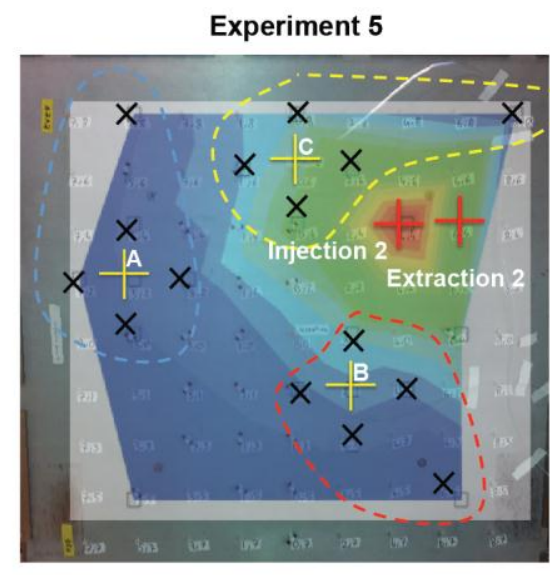

Experiment 4: source 1

Experiment 5: source 2

Experiment 6: sources 1 and 2 

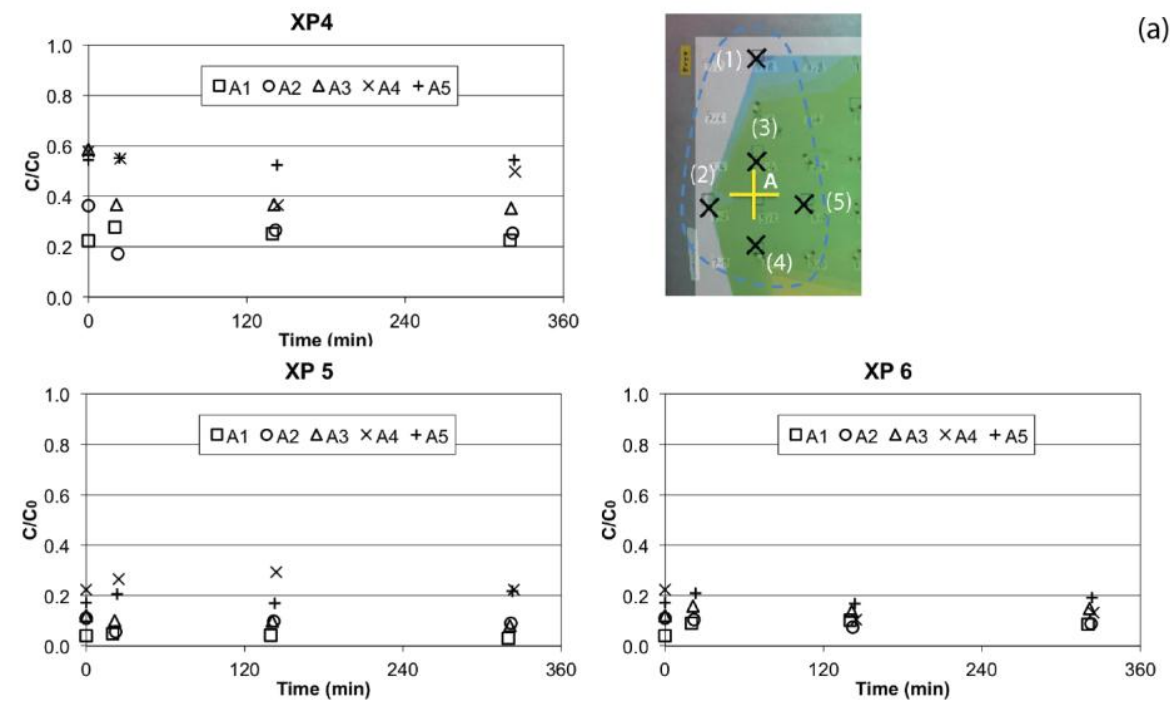

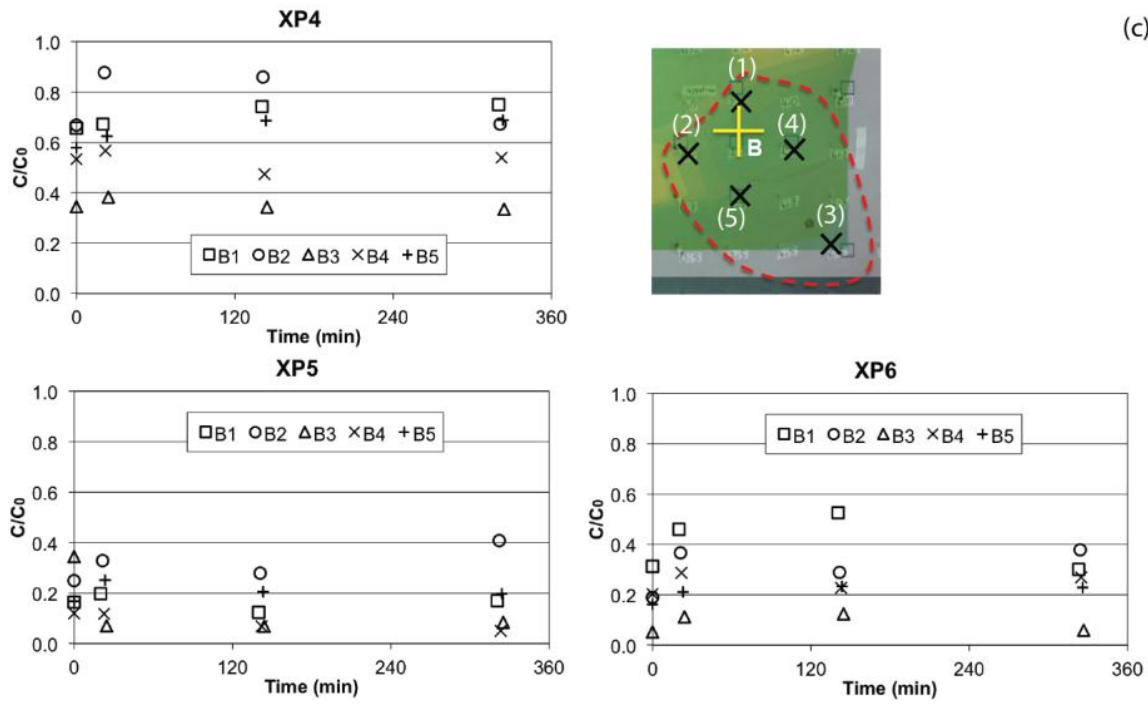
XP4

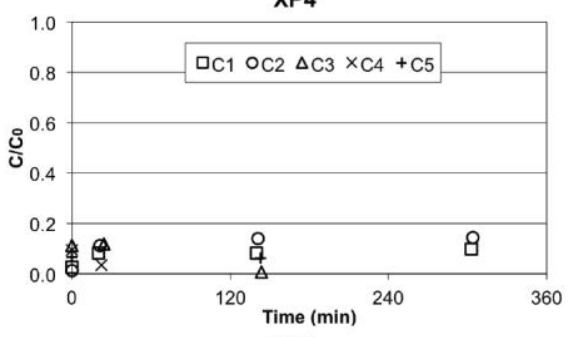

XP5

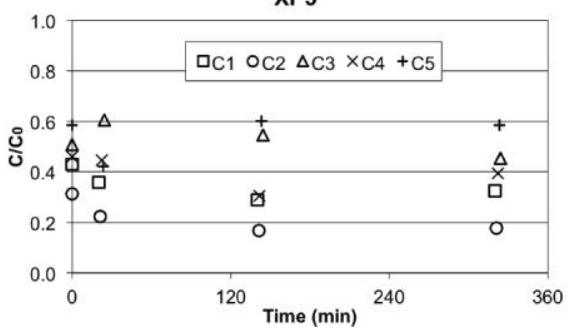

(b)

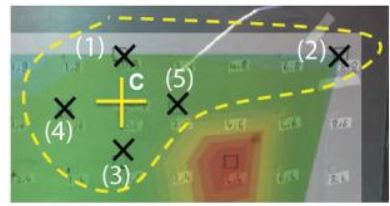

XP6

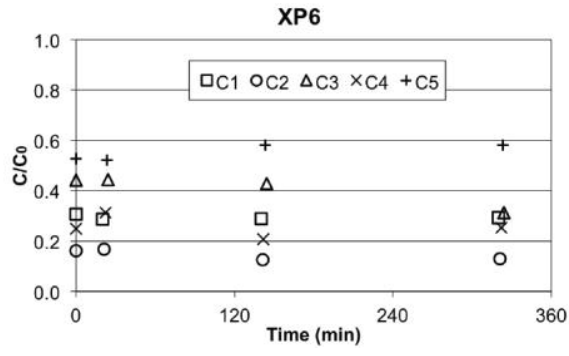



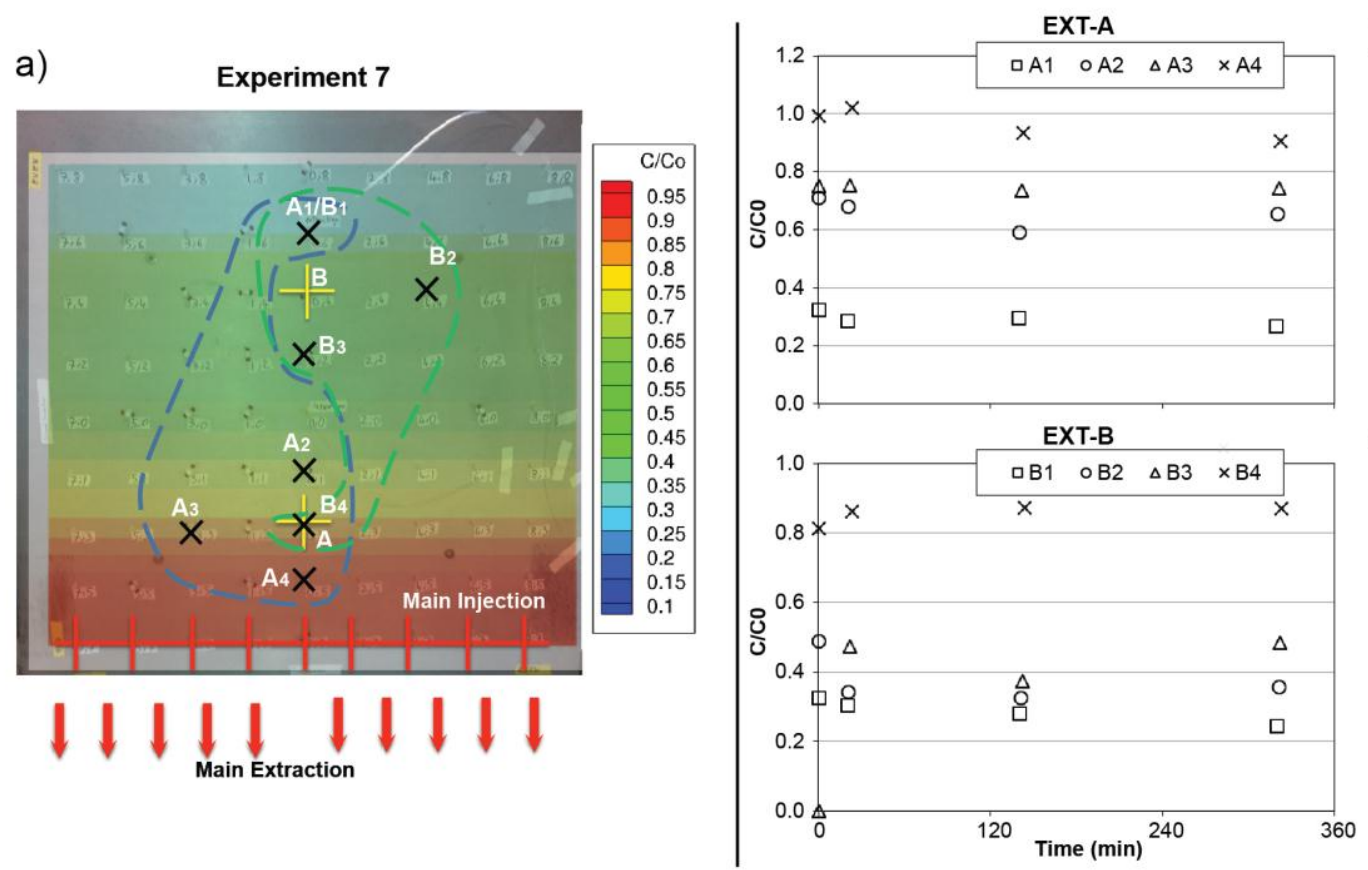

b)

c) 
a)

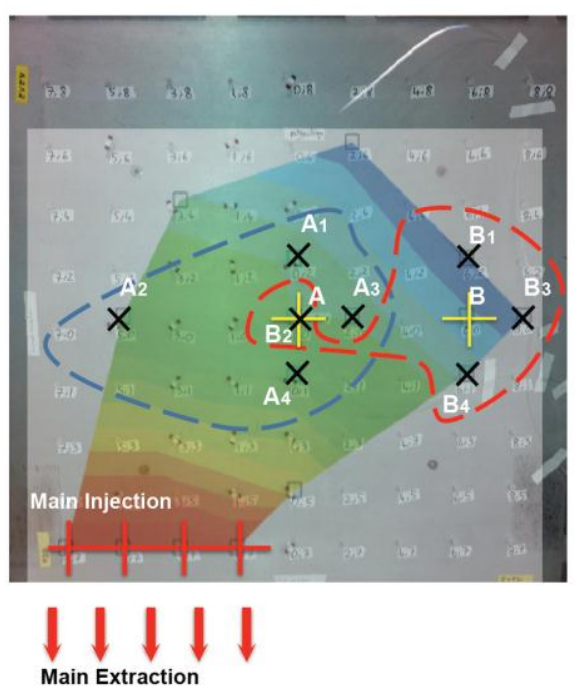

EXT-A

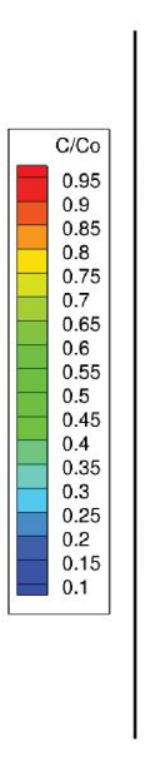

b)

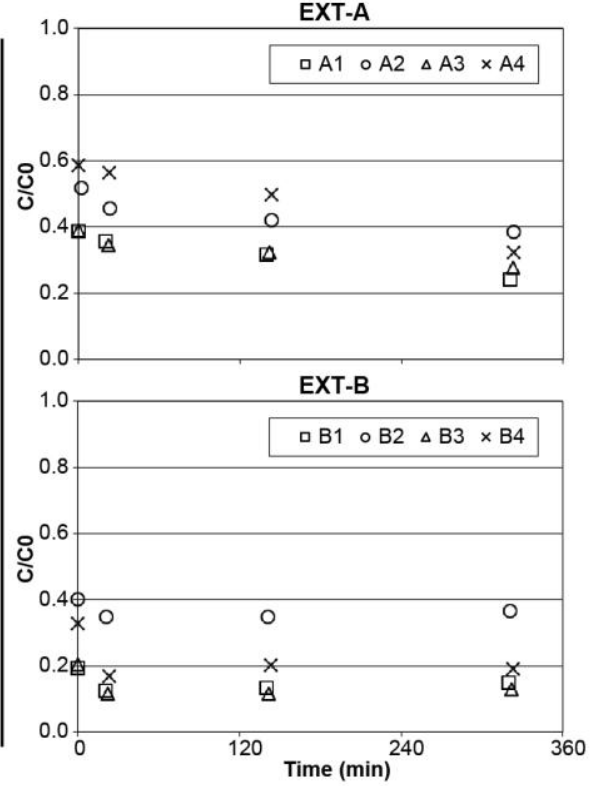

c) 
Source

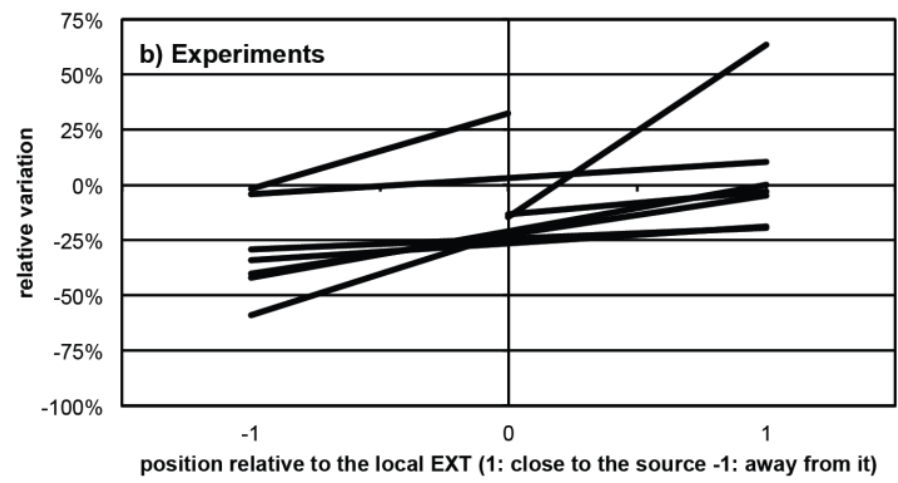

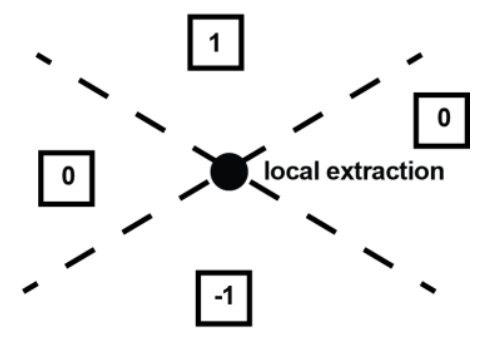

a) Schematic for position relative to the local extraction 